\title{
In-Space Structural Assembly: Applications and Technology
}

\author{
W. Keith Belvin ${ }^{1}$, Bill R. Doggett ${ }^{2}$, Judith J. Watson ${ }^{3}$, John T. Dorsey ${ }^{4}$, Jay Warren ${ }^{5}$, \\ Thomas C. Jones ${ }^{6}$, Erik E. Komendera ${ }^{7}$, Troy O. Mann ${ }^{8}$ and Lynn Bowman ${ }^{9}$ \\ NASA Langley Research Center, Hampton, Virginia, 23681-2199
}

\begin{abstract}
As NASA exploration moves beyond earth's orbit, the need exists for long duration space systems that are resilient to events that compromise safety and performance. Fortunately, technology advances in autonomy, robotic manipulators, and modular plug-and-play architectures over the past two decades have made in-space vehicle assembly and servicing possible at acceptable cost and risk. This study evaluates future space systems needed to support scientific observatories and human/robotic Mars exploration to assess key structural design considerations. The impact of in-space assembly is discussed to identify gaps in structural technology and opportunities for new vehicle designs to support NASA's future long duration missions.
\end{abstract}

$\begin{array}{ll}A D & =\text { atmospheric decelerator } \\ A G & =\text { artificial gravity } \\ A M & =\text { additive manufacturing } \\ A R V & =\text { asteroid redirect vehicle } \\ \text { EAM } & =\text { exploration augmentation module } \\ H D S T & =\text { high definition space telescope } \\ I S A & =\text { in-space assembly } \\ I S R U & =\text { in-situ resource utilization } \\ I S S & =\text { international space station } \\ J W S T & =\text { James Webb space telescope } \\ S E P & =\text { solar electric propulsion } \\ T A & =\text { technology area }\end{array}$

\section{Nomenclature}

\section{Introduction}

Government and commercial spacecraft have developed into high performance systems over the past four decades. New knowledge gained by robotic scientific observatories like the Hubble Space Telescope and the Mars rovers have resulted in the rewrite of educational textbooks several times. Hundreds of commercial communication satellites fill the geo-synchronous orbit and provide valuable financial returns to businesses in the United States and in other nations. For most applications, these government and commercial spacecraft are launched as a single unit often with deployable appendages to fit within the launch vehicle fairing.

In-space assembly (ISA) of spacecraft systems has been proposed and demonstrated several times as a way of improving aperture size, decreasing deployment risk, assembling systems too large to fit into a single launch vehicle, and enabling repair and upgrade. Assembly of spacecraft components also permits a "pay-as-you-go" approach to missions whereby space systems can be augmented for increased performance over time as way of lowering initial costs. The International Space Station (ISS) and the Hubble Space Telescope servicing missions are two good examples of ISA operations.

\footnotetext{
${ }^{1}$ Senior Researcher, Structural Mechanics and Concepts Branch, MS 190, Associate Fellow.

${ }^{2}$ Senior Researcher, Structural Mechanics and Concepts Branch, MS 190, Associate Fellow.

${ }^{3}$ Senior Researcher Engineer, Structural Mechanics and Concepts Branch, MS 190, AIAA Senior Member.

${ }^{4}$ Senior Researcher, Structural Mechanics and Concepts Branch, MS 190, Associate Fellow.

${ }^{5}$ Research Aerospace Engineer, Structural Dynamics Branch, MS 230, Member

${ }^{6}$ Research Engineer, Structural Mechanics and Concepts Branch, MS 190, Member.

${ }^{7}$ Research Engineer, Structural Mechanics and Concepts Branch, MS 190, Member.

${ }^{8}$ Assistant Branch Head, Structural and Thermal Systems Branch, MS 431, Senior Member.

${ }^{9}$ Portfolio Project Manager, Space Exploration and Technology Directorate, MS 494.
} 
Over the last decade, remarkable advances in robotics and autonomous operations have made ISA more affordable than prior efforts. This paper takes a forward look at potential NASA applications of ISA, reviews previous technology demonstrations of ISA, and projects key technology advancements needed for modular spacecraft design and joining of components and subsystems. Of particular interest to the astrophysics community is the possible use of ISA technology for future planet imaging telescopes. This class of telescope, with 10-meter to 20-meter diameter primary mirrors, far exceeds the launch shroud diameter of even the Space Launch System ${ }^{1}$.

Based on future mission needs, NASA released an update to its technology area (TA) roadmaps ${ }^{2}$ in May 2015. ISA of spacecraft systems including large apertures for science is highlighted as a technology goal in several roadmaps: TA-4 Robotics and Autonomous Systems; TA-7 Human Exploration Destination Systems; TA-8 Science Instruments, Observatories, and Sensor Systems; and TA-12 Materials, Structures, Mechanical Systems, and Manufacturing. The need for on-orbit servicing, particularly in geo-synchronous orbit ${ }^{3}$, modularity and reconfigurability of design ${ }^{4-5}$, and in-space aggregation and assembly ${ }^{6}$ is well documented.

To understand the state of the art and gaps in ISA technology and capabilities, this paper reviews the key design drivers for future NASA vehicles and space systems. These results are proffered to guide structural systems research and development efforts in order to make ISA a routine capability for future space vehicle design and operations.

\section{Possible NASA Applications of ISA}

NASA's science and exploration missions of the future require spacecraft systems, both robotic and human tended, that can operate in deep space for extended periods of time. In this section, the authors assess a number of possible spacecraft systems that could potentially support NASA space science and exploration. Each of these spacecraft types was attributed high-level requirements, design options, and technology drivers to identify technology needs that apply to multiple vehicles (crosscutting). For each spacecraft system, three categories are used to guide the assessment: 1) structural requirements describe the primary functional and performance aspects of the space system, 2) vehicle design options indicate the approaches the designer may consider for assembly, deployment, and space operations; and 3) key mechanical/structural technologies represent technologies needed to achieve the structural requirements for a given spacecraft type. Note that mass is a design driver in all space applications, but only those space systems requiring very low mass are noted with low mass as a requirement.

\section{A. Asteroid Redirect Vehicle}

An Asteroid Redirect Vehicle (ARV) ${ }^{7}$ in cis-lunar space consists of a robotic capture device, large solar arrays for power and electric propulsion. The ARV could dock with crewed modules such as Orion and other augmentation modules (Fig. 1). The Exploration Augmentation Module (EAM) could be used to test deep space habitation technologies for a Mars transport habitat. The EAM could also be repurposed as a cis-lunar exploration platform that advances scientific research, enables lunar surface exploration and provides a deep-space vehicle assembly and servicing site.

The ARV (docked with crewed modules) key structures requirements, design options, and technology needs are described as:

1) Structural Requirements

a. Pressurized volume with airlocks and docking ports

b. High strength and stiffness

c. Assembly (or deployment) of subsystem modules

2) Vehicle Design Options

a. Module-based design for docking/berthing

b. Modular subsystems for repair/assembly/upgrade

c. Long reach arms for berthing/inspection/assembly

3) Key Mechanical/Structural Technologies

a. Soft-docking systems

b. Serviceable/modular components

c. Robotic manipulator and end effectors

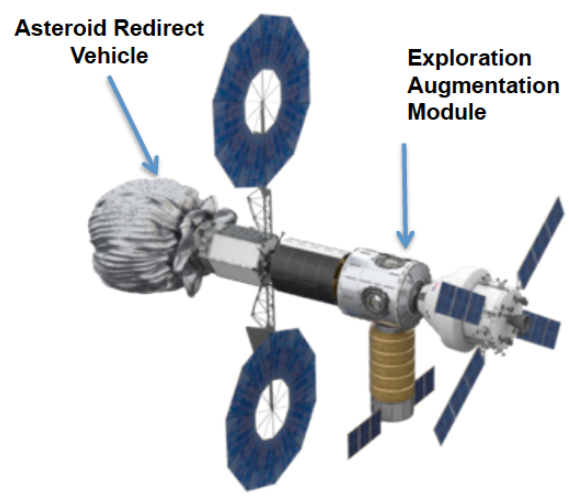

Figure 1. Mission concept for Asteroid Redirect Vehicle. 


\section{B. Artificial Gravity Vehicles}

Various concepts for artificial gravity (AG) vehicles have been evaluated as shown for example in Fig. 2. In 1985 the Shuttle/Spacelab D-1 mission flew a biorack centrifuge containing seeds, bacteria, and human blood cells. The results were summarized in Ref. 8: "microgravity effects at the cellular level may be eliminated by artificial gravity". The study assumed that a centripetal acceleration of $1-\mathrm{g}$ would be physiologically equivalent to a gravitational acceleration of 1-g (excluding Coriolis effects). Based on these results, Ref. 9 studied artificial gravity (AG) countermeasures for an 18 month, six crew mission with 1-g of AG produced by spinning a space vehicle as shown in Fig. 2. More recently, an international workshop on AG evaluated the efficacy of several vehicle concepts ${ }^{10}$.

The AG vehicle key structures requirements, design options, and technologies are described as:

1) Structural Requirements

a. Pressurized space with airlocks and docking ports

b. High strength and stiffness truss $(0.34-1.0 \mathrm{~g})$

c. Assembly (or deployment) of modules

d. Robust to docking loads

2) Vehicle Design Options

a. Module based design for berthing/docking

b. Deployment/assembly

3) Key Mechanical/Structural Technologies

a. High strength and stability

b. Truss assembly and joining technology

c. Robotic berthing/assembly

d. Modular components and docking systems

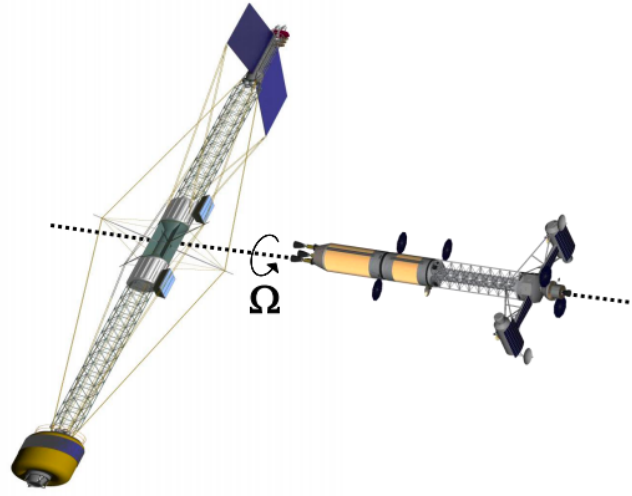

Figure 2. Artificial Gravity Vehicle.

\section{Space Dock ("Transportation Hub")}

The International Space Station has proven that by aggregating payloads in one location, coupled with a dexterous robotics infrastructure, complex ISA and repair operations are enabled. Concepts for general-purpose in-space construction facilities and space cranes have been under consideration for decades ${ }^{11-12}$. Snead ${ }^{13}$ argues that to seriously create rapid growth in space, an on-orbit logistics capability is required. This on-orbit logistics capability (Fig. 3), referred to herein as a Space Dock, could proceed from the ISS experience. In fact, the Defense Advanced Research Projects Agency (DARPA) is promoting a future of spaceflight that involves building, refueling and repairing spacecraft in a depot far from Earth. "We think that these capabilities - space capabilities - are not just about a single monolithic satellite with a few capabilities, but instead about a vibrant, robust ecosystem that involves transportation, repair, refueling, upgrading, and in-situ construction." ${ }^{14}$.

The Space Dock key structures requirements, design options, and technologies are described as:

1) Structural Requirements

a. High strength and stiffness truss

b. Structural metrology platform

c. Robotics - crawler/spider/free-flyer robots

d. Docking/berthing infrastructure

e. Fuel storage

2) Vehicle Design Options

a. Large ( $\sim 10$ s meters $)$ truss, with power and manipulators

b. Pre-positioning of infrastructure

c. Repair and assembly

3) Key Mechanical/Structural Technologies
a. Assembled truss
b. Power/data/mechanical joining technology
c. Metrology
d. Long-reach manipulators

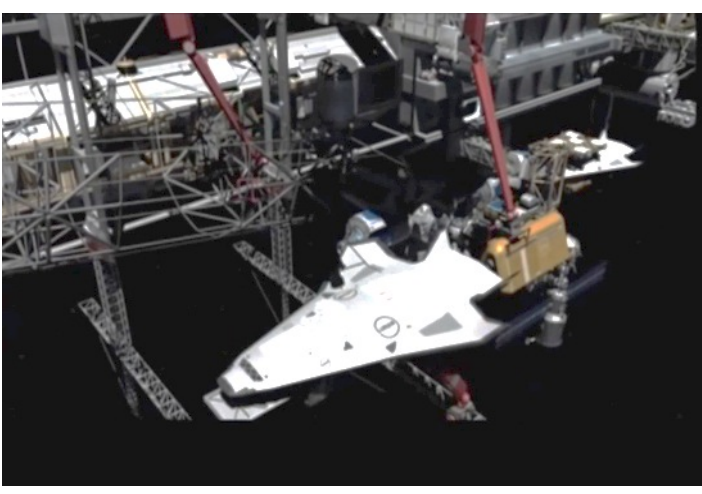

Figure 3. Space Dock Servicing Facility. 


\section{High Definition Space Telescope}

Various studies ${ }^{15-17}$ have been performed to identify the requirements for the next large astrophysics observatory beyond the James Webb Space Telescope (JWST). These studies have considered a range of telescope sizes as shown in Figure 4. One concept referred to as the High Definition Space Telescope (HDST) ${ }^{18}$ would utilize a $10 \mathrm{~m}$ to $12 \mathrm{~m}$ telescope operating at $0.1 \mu \mathrm{m}$ to $2 \mu \mathrm{m}$ wavelengths (not a cryogenic telescope). It would use a coronagraph for imaging and spectroscopy of Earth-like exoplanets. The structural stability of the HDST would need to be on the order of tens of picometers. Servicing for upgrade and repair similar to that done for the Hubble Space Telescope would be needed for life extension.

Due to the large size of the telescope, either highly complex deployment or ISA would be required. ISA enables new design paradigms; for example, the possibility of using multiple small launchers to aggregate the telescope components for assembly instead of launching one large system.

A key consideration of ISA for telescopes is the stability of the joined segments. Bartoszyk's [19] work on non-ISA joints for the James Webb Space Telescope showed that bonded joint stability can be achieved even at cryogenic temperatures. ISA joining technology (mechanical latching, bonding, and welding) and the relative stability of the joined system for each method are primary design drivers for space telescope assembly.
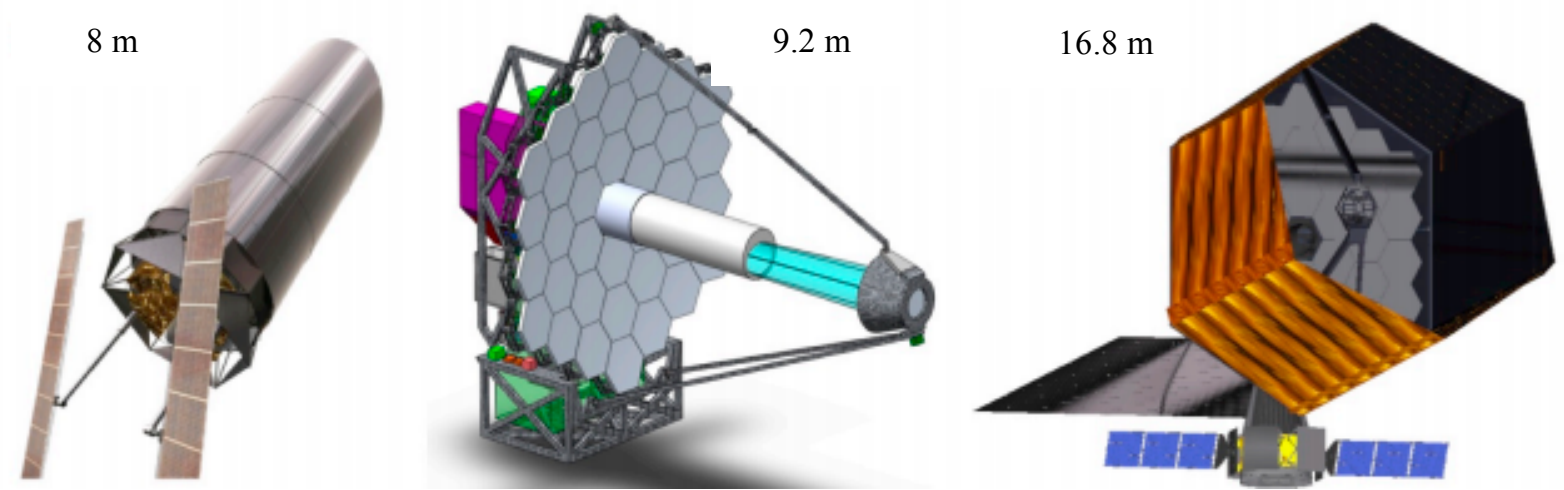

Figure 4. Telescope concepts ${ }^{8}: 8 \mathrm{~m}$ monolithic design; $9.2 \mathrm{~m}$ segmented design; and $16.8 \mathrm{~m}$ segmented design.

The HDST key structures requirements, design options, and key technologies are described as:

1) Structural Requirements

a. Deployment and/or assembly of primary mirror (12-20 m diameter)

b. High dimensional stability (10s of picometers)

c. Sunshield

d. Optical bench and secondary mirror support

2) Vehicle Design Options

a. Deployable (JWST derivative)

b. In-space assembly

c. Modules (mirrors, instruments, etc.)

d. Optical bench and secondary mirror truss

3) Key Mechanical/Structural Technologies
a. Micro-stability of joints
b. Power/data/mechanical joining
c. Robotic assembly
d. Integrated power/instrument modular structural component

\section{E. Surface In-Situ Resource Utilization (ISRU) for Construction}

Surface operations at Mars and other locations in the solar system require in-situ resource utilization to achieve some level of earth independence for future exploration missions. In Ref. 20, the need for ISRU and a reusable orbiter for earth independent Mars missions is studied. The use of regolith is proposed for processing structural materials and manufacturing of structural systems in order to provide infrastructure for long duration human 
missions to Mars. Constructing infrastructure on Mars was also the subject of an advanced concepts study that developed a technique known as 'contour crafting'. Khoshnevis [21] presents simulations of this technique for building systems on the surface of Mars as shown in Fig. 5.

Requirements, design options, and technologies for construction using ISRU are described as:

1) Structural Requirements
a. Robotic processing of materials into useful forms
b. Mobility and dexterity
c. Pressure vessels
d. Surface and subsurface operations

2) Vehicle Design Options
a. Design with low strength materials (e.g. unreinforced polymers)
b. Modular assembly of sintered (ceramic) blocks
c. Assembly of processed parts into systems
d. Repair and assembly

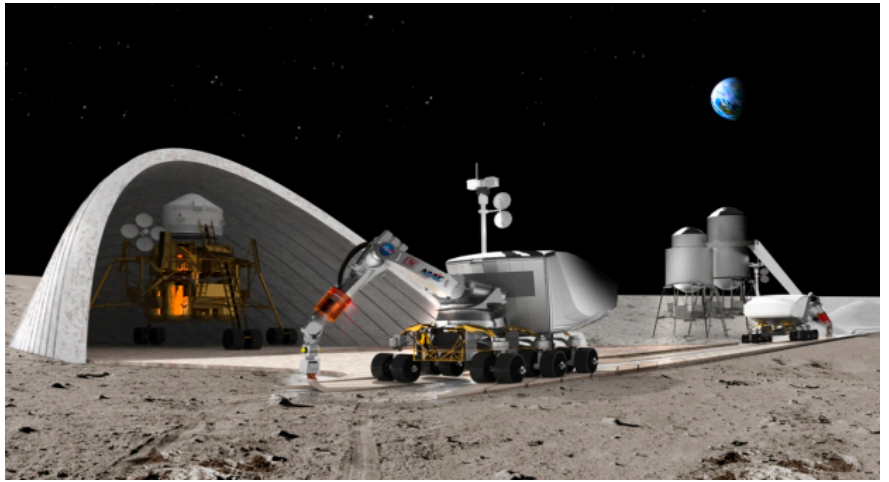

Figure 5. Surface ISRU and construction.

3) Key Mechanical/Structural Technologies
a. Additive manufacturing
b. Modular parts and assembly (joining technology) - "construction"
c. Mobility of systems (wheeled and robotic manipulators)
d. Regolith contouring and constituent extraction

\section{F. Solar Electric Power \& Propulsion}

The Deep Space 1 and Dawn spacecraft ${ }^{22}$, propelled by ion thrust, introduced the use of a new in-space propulsion technology. Now, very large solar electric propulsion (SEP) vehicles are under study for deep space missions as shown in Figure 6. Both SEP and large electric power systems are particularly attractive for missions ${ }^{23}$ to Mars and Phobos. For this class of mission to the vicinity of Mars, $100 \mathrm{~kW}$ to $400 \mathrm{~kW}$ of electric power is needed for reasonable transit times. Recent studies ${ }^{24}$ of these large SEP systems have shown the need for a high strength and stiffness backbone truss which, may be well suited to ISA.

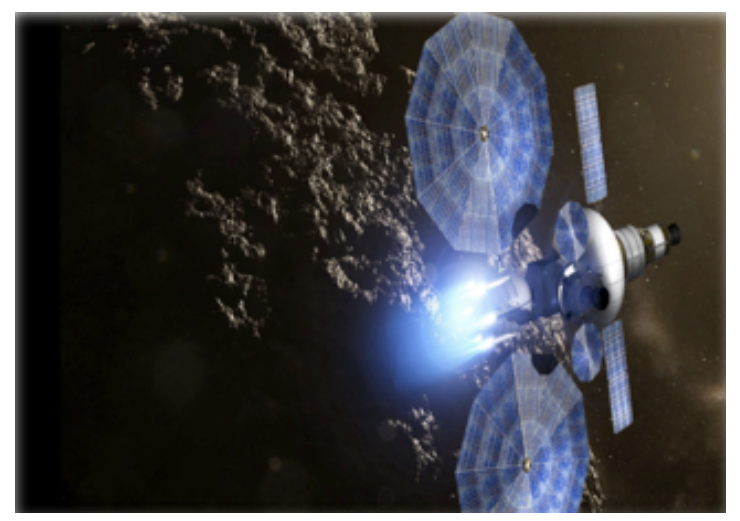

(a) Solar electric propulsion

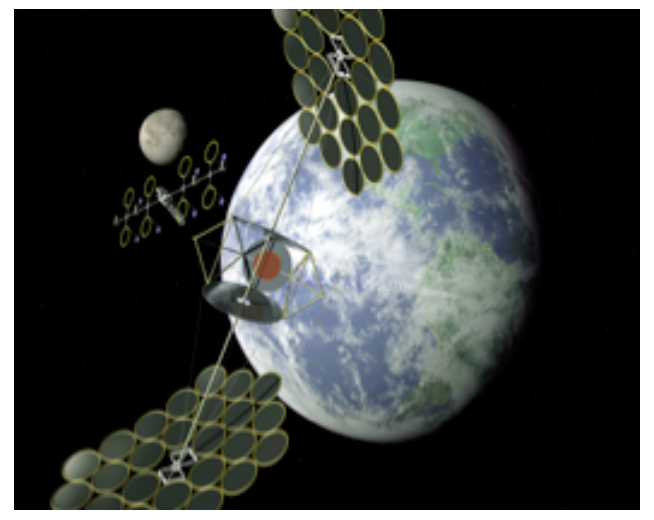

(b) Solar electric power

Figure 6. Artist's concept for solar electric space systems. 
The SEP vehicle key structures requirements, design options, and key technologies are described as:

1) Structural Requirements

a. Large support structures for high-power solar arrays

b. Low mass with high stiffness

2) Vehicle Design Options

a. Deployable and assembled arrays

b. Membrane deployment

c. High stiffness backbone truss

d. Active structural control

3) Key Mechanical/Structural Technologies
a. Assembly/disassembly of arrays
b. High power and mechanical/electrical joining technology
c. High power/mass efficiency

\section{G. Sun Shields / Star Shades}

Large sun shades for thermal and light control and occulter star shades for exoplanet imaging are critical elements of large scientific observatories. While these membrane dominated structures (Fig. 7) are well suited to packaging and deployment, the compressive members that maintain tension in the membranes often require complex deployments. With long reach autonomous manipulators, these systems could be assisted by robotics during deployment. In addition, servicing large scientific observatories with fully extended sun shades poses extreme reach challenges. The need for full or partial retraction of the sun shades could be facilitated with robotic assembly agents.

Star Light Shades primary structures requirements, design options, and technologies are described as:

1) Structural Requirements

a. Low mass, moderate stiffness

b. Large area membranes

2) Vehicle Design Options

a. Membrane deployment

b. Hybrid robotic assembly/deployment

3) Key Mechanical/Structural Technologies

a. Lightweight membrane deployment/assembly

b. Retraction for servicing desirable

c. Star shade-geometric shape precision

\section{H. Atmospheric Decelerators}

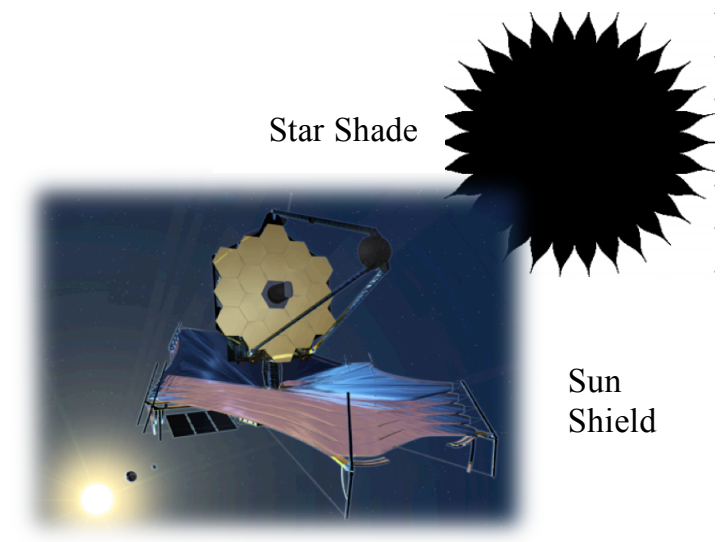

Figure 7. Sun shield and star shade.

Entry, descent, and landing is a critical capability for landing on planetary bodies with atmospheres. Detailed systems analysis studies ${ }^{25}$ of atmospheric decelerators have been performed and NASA is developing ever larger systems for future human missions to Mars. While not currently in the trade space, prior studies ${ }^{26}$ have investigated ISA of heatshields and aerobrakes. Current studies assume a landed payload mass of 27 metric tons which requires an $18 \mathrm{~m}$ heatshield diameter. Assembly of structural systems this size and larger is relatively straight forward if one assumes a truss backplane populated with panels made of appropriate thermal materials as shown in Fig. 8.

Key structures requirements for Atmospheric Decelerators (AD), design options, and technologies are described as:

1) Structural Requirements

a. High strength and stiffness

b. Robotics bench, crawler/spider/free-flyer robots

c. Docking/berthing infrastructure

2) Vehicle Design Options

a. Truss backplane

b. Pre-positioning (aggregation) of infrastructure

c. Assembly and inspection

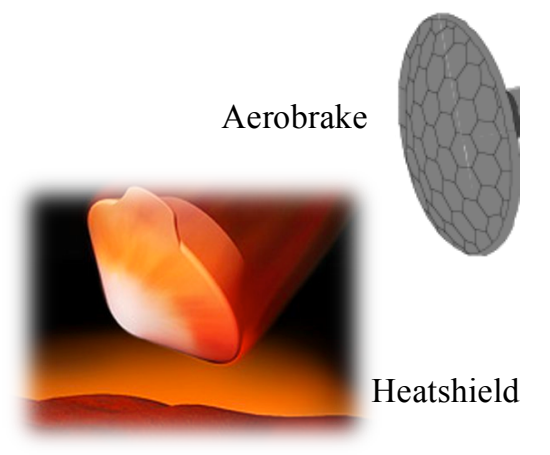

Figure 8. Heatshield and aerobrake. 
3) Key Mechanical/Structural Technologies
a. Assembled curved truss
b. Panel joining technology
c. Close-out of panel seams from hot gases
d. Thermal control - materials, hot structures

\section{Capability and Technology Needs}

From the previous section, the primary structural/mechanical capabilities for future NASA vehicles are shown in Table 1. The most frequently occurring (crosscutting) capabilities include modular design with high stiffness, robotic assembly with long reach manipulators, mechanical and electrical joining technology for components and modules, docking and berthing, and deployable subsystems. The remaining capabilities in Table 1 are more application dependent.

From this analysis of high priority (crosscutting) needs for structural space systems, an assessment of current technology readiness is appropriate. In particular, the state-of-the-art in three key technology groupings are described next: structural assembly; autonomous robotics; and additive manufacturing.

Table 1. Crosscutting capabilities and requirements for future NASA vehicles

\begin{tabular}{|c|c|c|c|c|c|c|c|c|}
\hline & ARV & $\mathbf{A G}$ & $\begin{array}{l}\text { Space } \\
\text { Dock }\end{array}$ & HDST & ISRU & SEP & $\begin{array}{c}\text { Sun } \\
\text { Shade }\end{array}$ & AD \\
\hline Modular Design & $\mathrm{X}$ & $\mathrm{X}$ & $\mathrm{X}$ & $\mathrm{X}$ & $\mathrm{X}$ & $\mathrm{X}$ & & $\mathrm{X}$ \\
\hline High Stiffness & $\mathrm{X}$ & $\mathrm{X}$ & $\mathrm{X}$ & $\mathrm{X}$ & $\mathrm{X}$ & $\mathrm{X}$ & & $\mathrm{X}$ \\
\hline $\begin{array}{l}\text { Robotic Assembly / } \\
\text { Joining }\end{array}$ & & $\mathrm{X}$ & $\mathrm{X}$ & $\mathrm{X}$ & $\mathrm{X}$ & $\mathrm{X}$ & & $\mathrm{X}$ \\
\hline Long Reach Manipulation & & $\mathrm{X}$ & $\mathrm{X}$ & $\mathrm{X}$ & $\mathrm{X}$ & $\mathrm{X}$ & & $\mathrm{X}$ \\
\hline Power/Data/Mech. Joining & $\mathrm{X}$ & $\mathrm{X}$ & $\mathrm{X}$ & $\mathrm{X}$ & $\mathrm{X}$ & $\mathrm{X}$ & & \\
\hline Soft Docking / Berthing & $\mathrm{X}$ & $\mathrm{X}$ & $\mathrm{X}$ & $\mathrm{X}$ & & $\mathrm{X}$ & & $\mathrm{X}$ \\
\hline Deployable Subsystems & $\mathrm{X}$ & $\mathrm{X}$ & $\mathrm{X}$ & $\mathrm{X}$ & & $\mathrm{X}$ & $\mathrm{X}$ & \\
\hline Pressure Vessels & $\mathrm{X}$ & $\mathrm{X}$ & $\mathrm{X}$ & & $\mathrm{X}$ & & & \\
\hline Low Mass & & & & $\mathrm{X}$ & & $\mathrm{X}$ & $\mathrm{X}$ & $\mathrm{X}$ \\
\hline High Strength & $\mathrm{X}$ & $\mathrm{X}$ & $\mathrm{X}$ & & & $\mathrm{X}$ & & \\
\hline Membrane Deployment & & & & $\mathrm{X}$ & & $\mathrm{X}$ & $\mathrm{X}$ & \\
\hline Near Isothermal Control & & & & $\mathrm{X}$ & & & $\mathrm{X}$ & \\
\hline $\begin{array}{l}\text { High Dimensional } \\
\text { Stability }\end{array}$ & & & & $\mathrm{X}$ & & & $\mathrm{X}$ & \\
\hline $\begin{array}{l}\text { Additive Manuf. / } \\
\text { Welding }\end{array}$ & & & $\mathrm{X}$ & & $\mathrm{X}$ & & & \\
\hline MicroStabilitv of Joints & & & & $\mathrm{X}$ & & & & \\
\hline Surface Mobility & & & & & $\mathrm{X}$ & & & \\
\hline
\end{tabular}

\section{ISA Technology Readiness and Opportunities}

A number of past and present activities to develop and mature ISA capabilities have been undertaken by government, industry and academia. Many of these efforts are relevant for developing a new approach to space vehicle design involving modular assembly using robotic agents. 


\section{A. Structural Assembly}

Following the successful development of the Space Transportation System ("Space Shuttle"), the structures community has developed highly efficient deployable and erectable space structures. The work of Refs. 27-28 researched, developed and flight demonstrated the ability to assemble large ( $5 \mathrm{~m}$ bay size) truss structures in space. The assembly agents for these efforts were astronauts who served both as the controller and the robotic "end effector". Joint latches were specifically designed to be operated using the gloved hands of suited astronauts. Flight experiments showed that highly efficient space trusses could be constructed with predictable time estimates based on simulated assembly in neutral buoyancy facilities. These results spawned new designs and experiments to assemble a precision segmented reflector $^{29}$ for high-frequency antennae and various optical and near-infrared telescope applications.

Robotic assembly $\mathrm{y}^{30}$ of space systems was demonstrated for planar truss and beam structures in the automated structures assembly laboratory at NASA Langley Research Center. In these experiments, smart end effectors and mechanized joints were used with a general-purpose robotic motion system and optical metrology for computer control of all assembly operations. The control system was designed to provide for human supervision, but the assembly occurred in a totally autonomous mode.

The joining technology for assembled and deployed structures was studied extensively in Refs. 31-37. Joint dominated structures were shown to have non-linear micro-dynamic behavior that can impart vibrations in the structural system as energy is stored and released primarily due to thermal cycling. Recent work ${ }^{38-39}$ has focused on reducing the complexity of ISA structural systems and improving the precision of assembled parts using robotic jigging and welding of joints.

While deployable structures with revolute joints and latches are commonly used, new ISA-designed joints are needed to improve the micro-dynamic stability of joined structures for some applications. Ref. 19 shows that bonded joints can achieve the stability requirements for telescope applications. The opportunity exists for new joining approaches to be developed such as magnetic latching in future ISA operations. Of particular interest are reversible joints for disassembly and module replacement.

Modular design of space systems coupled with an ISA capability can reduce launch loads as compared to a preassembled spacecraft. Similar to the computer industries "plug-and-play" architecture, modular design must be coupled with standard interfaces to achieve full functionality for on-orbit upgrades. Advances in system approaches to non-traditional ISA based modular design are needed to achieve acceptable risk, reliability, and performance measures.

\section{B. Autonomous Robotics}

Autonomy for both space and terrestrial applications has made major advances over the last decade ${ }^{40-42}$. For example, The Orbital Express spacecraft were launched March 8, 2007 and completed the demonstration while achieving all mission success criteria and objectives. This quote from Refs. $43-44$ summarizes the program purpose: "The Orbital Express program was created to prove that the technical obstacles to satellite servicing were surmountable -- to "take the technical excuse off the table" as it were. This mission demonstrated short range and long range autonomous rendezvous, capture and berthing, on-orbit electronics upgrades, on-orbit refueling, and autonomous fly-around visual inspection using a demonstration client satellite."

A full summary of the autonomous rendezvous, proximity operations, docking, and undocking of the Orbital Express vehicles is presented in Ref. 45. This program was a major achievement in the aerospace industry showing that in-space transfer of orbit replacement units could be done autonomously. In fact, the technology to assemble small telescopes is now in development in academia ${ }^{46}$. From these efforts, it appears that state-of-the-art robotic autonomy can support ISA today, provided that the vehicles are designed for modular assembly with connectors that provide not only mechanical joining, but also power and data connectivity.

\section{In-Space Additive Manufacturing}

Additive manufacturing (AM or three-dimensional (3-D) printing) is another technical discipline at the intersection of robotic manufacturing and structural assembly. Free-form fabrication of near-net shape parts with metals ${ }^{47}$ and 
plastics $^{48}$, and development of optimized processes for micro-g fabrication are underway. By using these new AM capabilities, the possibilities for in-space assembly and fabrication are endless.

In fact, new design paradigms are emerging called "digital materials" ${ }^{49}$ where mass-efficient hierarchical structures can be created using AM. Large-scale space structures are envisioned using robotic mobility with AM technology as discussed in Ref. 50. The potential for using this technology in space is just now being investigated. Issues associated with thermal distortions, inferior material properties, and contamination from the by-products of processing represent some of the challenges to be overcome before widespread use of AM in space is practical. Nevertheless, AM technology will continue to be developed since it is enabling for long term exploration on Mars where in-situ resource utilization (ISRU) is mandatory.

Hybrid approaches involving AM joining of structural components instead of mechanical latching need to be explored. AM material systems that lend themselves to bonding and unbonding would be attractive for repair and repurposing of spacecraft components. Development of intelligent precision jigging robots ${ }^{38-39}$ and smart endeffectors to control geometric errors during the joining process are being investigated. Reducing system complexity, controlling manufacturing volatiles, and achieving the desired stiffness and strength for AM manufactured structures should be the focus of near-term AM research and development.

\section{V.Summary}

A review of in-space assembly applications for future NASA missions has identified key technology drivers; some are crosscutting and some are very specific to certain vehicle classes. Prior and current technology development efforts are presented to clarify the remaining gaps for a robust ISA capability for government and industry. In addition, a relatively new and potentially game-changing technology for ISA is additive manufacturing (3-D printing). This "push" technology combined with new ISA-based structural design approaches can make future spacecraft systems more affordable and reusable.

Autonomous robotic assembly has been demonstrated in space and advances in autonomy technology for terrestrial applications continues. The state-of-the-art appears to have moved beyond teleoperation to some form of "supervised autonomy" whereby human intervention is only required in special unanticipated circumstances. Continued work on modularity and standard interfaces is needed to achieve the full potential of robotic assembly of space systems.

Efficient structural assembly in space, namely structures with low mass and high-stiffness and strength, can be achieved by system-level design that takes advantage of robotic assembly. The key technology gaps in the structures discipline needed to provide robust ISA capabilities are the joining and unjoining technology (mechanical and electrical), design modularity, and mass efficient long reach manipulators.

It is the authors' intention to focus research and development efforts to close the remaining technology gaps for ISA (most of which are structures related). This will enable a new ISA-based spacecraft design capability that makes future systems more affordable than the current single-launch, single-use approach to space vehicle design. Modular, repairable spacecraft will provide for increased operational life and potential multi-mission applications through reuse of vehicle components. Continuing to develop technology that reduces complexity and risk of ISA operations will lead to lower cost, more resilient space systems for NASA's exploration and science missions.

\section{References}

\footnotetext{
${ }^{1}$ NASA, "Space Launch System," May 2015. http://www.nasa.gov/exploration/systems/sls/index.html

${ }^{2}$ NASA Office of Chief Technologist, "Draft 2015 NASA Technology Roadmaps," May 2015. http://www.nasa.gov/offices/oct/home/roadmaps/index.html

${ }^{3}$ Benedict, B. L., "Rationale for Need of In-Orbit Servicing Capabilities for GEO Spacecraft," AIAA- 20135444, Space Conference and Exposition, San Diego CA, Sept. 10-12, 2013.

${ }^{4}$ Barnhart, D., Will, P., Sullivan, B., Hunter, R., and Hill, L., "Creating a Sustainable Assembly Architecture for Next-Gen Space: The Phoenix Effect,” 30 $0^{\text {th }}$ Space Symposium, Colorado Springs CO, May 2014.
} 
${ }^{5}$ Erkorkmaz, C., Nimelman, M., and Ogilvie, A., "Spacecraft Payload Modularization for Operationally Responsive Space," $6^{\text {th }}$ Responsive Space Conference, Los Angeles, CA, April 28-May 1, 2008.

${ }^{6}$ Troutman, P. A., et al., "Orbital Aggregation and Space Infrastructure Systems (OASIS)," IAC-02IAA.13.2.06, $53^{\text {rd }}$ International Astronautical Congress, Houston Texas, Oct. 10-19, 2002.

${ }^{7}$ Stich, S., "Astronauts and Robots: Human Exploration and Operations," NASA Johnson Space Center, June.

2015. http://www.slideshare.net/astrosociety/astronauts-robots-201505121515stich

${ }^{8}$ Shipov, A.A, "Space Biology and Medicine," edited by A. E. Nicogossian, S.R. Mohler, O.G. Gazenko, A.I. Grigoriev, eds. American Institute of Aeronautics and Astronautics, Reston, VA, 1997, pp. 349-363.

${ }^{9}$ Joosten, K. B., "Preliminary Assessment of Artificial Gravity Impacts to Deep-Space Vehicle Design," NASA

JSC-63473, NASA Feb. 2007.

${ }^{10}$ Paloski, W. H., and Charles, J. B., "2014 International Workshop on Research and Operational Consideration for Artifical Gravity Countermeasures, NASA TM-2014-217394, July 2014.

${ }^{11}$ Mikulas, M. M. Jr., and Dorsey, J. T., "An Integrated In-Space Construction Facility for the $21{ }^{\text {st }}$ Century, AAS 88-167," The $21^{\text {st }}$ Century in Space, Vol. 70, American Astronautical Sciences, 1990.

${ }^{12}$ Dorsey, J. T., Sutter, T. R., and Wu, K. C., "Structurally Adaptive Space Crane Concept for Assembling Space Systems on Orbit," NASA TP 3307, Nov. 1992.

${ }^{13}$ Snead, J. M., "Architecting Rapid Growth in Space Logistics Capabilities," AIAA 2004-4068, $40^{\text {th }}$ AIAA/ASME/SAE/ASEE Joint Propulsion Conference and Exhibit, Fort Lauderdale, FL, July 11-14, 2004.

${ }^{14}$ Wall, M., "Military Foresees Robot-Run 'Transportation Hub' in Space," Space.com, Sept. 14, 2015. http://www.space.com/30529-darpa-robotic-space-transportation-hub.html

${ }^{15}$ Postman, M., et al., "Advanced Technology Large-Aperture Space Telescope (ATLAST): A Technology Roadmap for the Next Decade," 2009. Report also on line at http://www.stsci.edu/institute/atlast

${ }^{16}$ Postman, M., et al., "The Advanced Technology Large Aperture Space Telescope (ATLAST): Science Drivers and Technology Developments," 2011. http://ntrs.nasa.gov/archive/nasa/casi.ntrs.nasa.gov/20110023497.pdf

${ }^{17}$ Coulter, D., "Beyond JWST: Future NASA Telescopes for Space and Earth Science," AIAA Space

Conference, Pasadena, California, September 11-13, 2012. http://hdl.handle.net.2014/43164

${ }^{18}$ AURA Report, "From Cosmic Birth to Living Earths," Association of Universities for Research in Astronomy, July, 2015. http://www.hdstvision.org/

${ }^{19}$ Bartoszyk, A., et al., "Design/Analysis of the JWST ISIM Bonded Joints for Survivability at Cryogenic Temperatures," Published in SPIE Proceedings Vol. 5868: Optical Materials and Structures Technologies II, Aug. 19, 2005.

${ }^{20}$ Arney, D. C., Jones, C. A., Klovstad, J. J., Komar, D. R., Earle, K., Moses, R., and Shyface, H., "Sustaining Human Presence on Mars Using ISRU and a Reusable Lander," AIAA 2015-4479, AIAA SPACE 2015 Conference and Exposition, Pasadena, California, Sep. 31, 2015.

${ }^{21}$ Khoshnevis, B., Carlson, A., Leach, N., Thangavelu, M., "Contour Crafting Simulation Plan for Lunar Settlement Infrastructure Build-up," NASA NIAC Phase-I Final Project Report, Oct. 2012.

${ }^{22}$ Choueiri, E. Y., "New Dawn for Electric Rockets," Scientific American, Feb. 2009. http://alfven.princeton.edu/papers/sciam2009.pdf

${ }^{23}$ Humphrey W. P., Baker, J. D., Strange, N. J., and Woolley, R. C., "Human Missions to Mars Orbit, Phobos, and Mars Surface Using 100-kWe-Class Solar Electric Propulsion," AIAA 2014-4436, AIAA SPACE 2014 Conference and Exposition, San Diego, CA, 4-7 August 2014.

${ }^{24}$ Mikulas, M., Pappa, R., Warren, J., and Rose, G., "Telescoping Solar Array Concept for Achieving High Packaging Efficiency,” AIAA-2015-1398, AIAA SciTech, Kissimmee, FL, Jan. 5-9, 2015.

${ }^{25}$ Zang, T. A., et. al., "Overview of the NASA Entry, Descent and Landing Systems Analysis Study," AIAA2010- 8649, AIAA Space 2010 Conference and Exposition, Anaheim, CA. August, 2010.

${ }^{26}$ Dorsey, J. T., and Dyess, J. W., "Structural Performance of Two Aerobrake Hexagonal Heat Shield Panel Concepts," NASA TM 4372, May 1992.

${ }^{27}$ Heard, W. L. Jr., Watson, J. J., Ross, J. L., Spring, S. C., and Cleave, M. L., "Results of the Access Space Construction Shuttle Flight Experiment," 2nd Aerospace Maintenance Conference, Aerospace Research Council, ARC-86-1186, Long Beach, CA, May 1986.

${ }^{28}$ Watson, J. J., Collins, T. J., and Bush, H. G., "A History of Astronaut Construction of Large Space Structures at NASA Langley Research Center,” IEEE Aerospace Conference Proceedings, Vol.7, 2002, pp. 3569-3587. 
${ }^{29}$ Collins, T. J., Fichter, W. B., Adams, R. R., and Javeed, M., "Structural Analysis and Testing of an Erectable Truss for Precision Segmented Reflector Application," NASA Technical Paper, TP-3518, July 1995.

${ }^{30}$ Doggett, W. R., "Robotic Assembly of Truss Structures for Space Systems and Future Research Plans," IEEE Aerospace Conference Proceedings, Vol. 7, 2002, pp. 3589-3598.

${ }^{31}$ Bush, H.G., Mikulas, M. M., and Wallsom, R. E., "Mechanical End Joint System for Connecting Structural Column Elements," United States Patent, No. 4,963,052, Oct. 16, 1990.

${ }^{32}$ Belvin, W. K., "Modeling of Joints for the Dynamic Analysis of Truss Structures," NASA Technical Paper, TP-2661, May 1987.

${ }^{33}$ Rule, W. K., and Thomas, F. P., "Welded Joints for Robotic, On-Orbit Assembly of Space Structures," Journal Aerospace Engineering, Vol. 7, 1994, pp. 209-224.

${ }^{34}$ Lake, M. S., Warren, P. A., and Peterson, L. D., "A Revolute Joint with Linear Load-Displacement Response for Precision Deployable Structures," Proceedings of the AIAA/ASME/ASCE/AHS/ASC37th Structures, Structural Dynamics, and Materials Conference, AIAA, Reston, VA, 1996, pp. 1639- 1647.

${ }^{35}$ Warren, P. A., Peterson, L. D., and Hinkle J. D., "Submicron Mechanical Stability of a Prototype Deployable Space Telescope Support Structure," Journal of Spacecraft and Rockets, Vol. 36, 1999, pp.765-771.

${ }^{36}$ Levine, M. B., "Microdynamic Behavior of a Joint Dominated Structure On-Orbit," AIAA 99-1267, $40^{\text {th }}$ AIAA/ASME/AHS, Structures, Structural Dynamics and Materials Conference, Saint Louis, MO, April 1999.

${ }^{37}$ Stohlman, O. R., "Repeatability of Joint-Dominated Deployable Masts," (2011) Ph.D. Dissertation, California Institute of Technology, 2011.

${ }^{38}$ Dorsey, J. T., Doggett, W. R., Hafley, R. A., Komendera, E., Correll, N., and King, B., "An Efficient and Versatile Means for Assembling and Manufacturing Systems in Space," AIAA-2012-5115, AIAA Space 2012 Conference and Exposition, Pasadena, CA, Sept. 11-13, 2012.

${ }^{39}$ Komendera, E., "Precise Assembly of Truss Structures by Distributed Robots," PhD Dissertation, University of Colorado, 2014.

${ }^{40}$ Zimpfer, D., Kachmar, P., and Tuboy, S., "Autonomous Rendezvous, Capture and In-Space Assembly: Past, Present and Future," AIAA 2005-2523, $1^{\text {st }}$ Space Exploration Conference, Orlando FL, Jan. 30-Feb. 1, 2005.

${ }^{41}$ Chouinard, C., Knight, R., Jones, G., Tran, D., and Koblick, D., "Automated and Adaptive Mission Planning for Orbital Express," AIAA-2008-3383, SpaceOps Conference, 2008.

${ }^{42}$ Ogilive, A., Allport, J., Hannah, M., and Lymer, J., "Autonomous Robotic Operations for On-Orbit Satellite Servicing," Proc. SPIE 6958, Sensors and Systems for Space Applications II, 695809, April 15, 2008.

${ }^{43}$ Friend, R., "Orbital Express Program Summary and Mission Overview," Sensors and Systems for Space Applications II, Proc. of SPIE, Vol. 6958, 2008.

${ }^{44}$ Boeing Company, "Orbital Express Program Summary and Flight Results," AIAA Space 2007 Conference and Exposition, Long Beach, CA, 19-20 Sept. 2007.

${ }^{45}$ Dennehy, C. J., and Carpenter, J. R., "A Summary of the Rendezvous, Proximity Operations, Docking, and Undocking (RPODU) Lessons Learned from the Defense Advanced Research Project Agency DARPA) Orbital Express (OD) Demonstration System Mission,” NASA TM-2011-217088, April 2011.

${ }^{46}$ Underwood, C., and Pellegrino, S., "Autonomous Assembly of a Reconfigurable Space Telescope (AAReST) - A CubeSat/Microsatellite Based Technology Demonstrator," $27^{\text {th }}$ AIAA/USU Conference on Small Satellites, Aug. 10-11, 2013.

${ }^{47}$ Hafley, R. A., Taminger, K. M., and Bird, K. R., "Electron Beam Freeform Fabrication in the Space Environment," Presented at the 45th AIAA Aerospace Sciences Meeting and Exhibit, Reno, NV, Jan. 8-11, 2007.

${ }^{48}$ Snyder, M. P., Dunn, J. J., and Gonzalez, E. G., "Effects of Microgravity on Extrusion based Additive Manufacturing," AIAA 2013-5439, AIAA Space Conference and Exposition, San Diego, CA, Sept. 10-12, 2013.

${ }^{49}$ Cheung, K. C., "Digital Cellular Solids: Reconfigurable Composite Materials," PhD Dissertation, Massachusetts Institute of Technology, 2012.

${ }^{50}$ Hoyt, R. P., et al., "SpiderFab: An Architecture for Self-Fabrication Space Systems," AIAA -5509, AIAA Space Conference and Exposition, San Diego, CA, Sept. 10-12, 2013. 